Article

\title{
Unintended Consequences and Risk(y) Thinking: The Shaping of Consequences and Responsibilities in Relation to Environmental Disasters
}

\author{
Rolf Lidskog * (1) and Daniel Sjödin (1) \\ Environmental Sociology Section, School of Humanities, Educational and Social Sciences, Örebro University, \\ SE-701 82 Örebro, Sweden; daniel.sjodin@oru.se \\ * Correspondence: rolf.lidskog@oru.se; Tel.: +46-19-303-272
}

Received: 27 June 2018; Accepted: 14 August 2018; Published: 16 August 2018

\begin{abstract}
Unintended consequences have long been central for the social sciences. But, the development of risk analysis and the adoption of risk language have substantial implications for how to understand and evaluate unintended consequences. Claims can now be raised that unintended consequences should have been foreseen and other options chosen. This situation constitutes the starting point for this paper, which develops an understanding of unintended consequences, in particular, in relation to environmental disasters. It draws on Robert Merton's classic work on unanticipated consequences, but refines and further develops it by fertilizing it with findings from risk sociology and framing theory. A particular case of a human-caused disaster, a severe wildfire, is analyzed to illustrate and expand the understanding of unintended consequences. The empirical material consists of a postal survey to everyone directly affected by the wildfire ( $N=960$ individuals). The empirical results of this analysis are then explained and used to improve the understanding of unintended consequences, by showing how the context and framing of the disaster heavily affected the evaluation of its consequences, including unintended ones.
\end{abstract}

Keywords: environmental disaster; forest fires; responsibilization; risk; unintended consequences

\section{Introduction}

Unintended consequences are a driving force in human history, states Ulrich Beck in his seminal book Risk Society [1]. He claims that human planning and technical development have resulted not only in material wealth, but also in a dramatic increase in the generation of risks, risks of such a magnitude that they are currently transforming the fundamental structure of society. Hitherto unintended consequences have been legitimated, partly by reference to the production of wealth, and partly by society's development of precaution and compensation systems (i.e., the positive and preventive sides of risk-taking). Currently, however, these risks are becoming more widespread and serious than ever before, and can no longer be seen as latent side-effects afflicting limited localities or groups. Thus, a feature of this new emerging society is that these risks can no longer be seen as manageable side-effects, but must, instead, actively be avoided.

Obviously, this grand narrative can be questioned. Intended consequences are also a driving force. The invention of democracy and the struggle to implement it are major human achievements, as are the institutionalization of human rights in national and international regulatory frameworks, and the development of social welfare systems, to give a handful of examples. Even if they are also followed by unintended consequences, this does not detract from the fact that intended consequences are an important driving force in human history. That said, Beck makes the important point that it is harder now to legitimate hazards and severe harms caused by human action by saying that they were unintentional. Due to the spread of risk consciousness, changes in regulatory style, increased 
media attention, and the efforts of organizations to appear trustworthy in the eyes of the public, risk management practices have been instituted in almost all sectors and across a wide range of organizational contexts. We have "a risk management of everything" as Michael Power puts it [2], which means that risk is an organizing concept within the public and private sectors, as well as in many aspects of people's everyday lives [3,4].

An increased emphasis on risk management and the adoption of a language of risk have substantial implication for the phenomenon of unintended consequences. Basically, risk analysis (risk characterization and assessment) includes the charting of possible consequences (probability distribution of modeled consequences), which means that the likelihood and potential effects of unintended consequences should be known. This makes it more difficult to legitimate negative consequences of decisions, even unintended ones. When unintended consequences appear, claims can be raised that they should have been possible to foresee, and other options should have been chosen to avoid these consequences. Thus, whereas the increased focus on risk management practices may result in some unintended consequences being avoided, in those cases where unintended consequences do appear, it may result in strong criticism being directed towards the organization that caused the consequences, or the regulatory framework that should have prevented them from arising.

This situation constitutes the starting point for this paper, which aims to elaborate a deeper understanding of unintended consequences, in particular, in relation to disasters. This is done in three steps. First, the conceptual meaning of unintended consequences will be discussed, drawing on Robert Merton's classic article on unanticipated consequences of social action, which is critically and constructively discussed in terms of findings from risk sociology and framing theory [5]. Thereafter, a particular disaster-the largest forest fire in Swedish modern history-is presented and analyzed, in order to show how our conceptual understanding of unintended consequences can be put into practice. The empirical material consists of a postal survey to persons directly affected by the forest fire ( $N=960$ individuals). This type of data-post facto evaluation by victims-is chosen to measure how they interpret and evaluate the disaster. The reason for selecting a disaster of this type is that such events are both unintended and have severe consequences, and claims can be raised that they should have been anticipated. In this sense, it serves as a critical case for discussing unintended consequences. In the third step, we return to the earlier discussion on unintended consequences by showing how the context and framing of the disaster heavily affected the evaluation of its consequences.

\section{Research Background: Unintended Consequences and Risk Analysis}

\subsection{Unanticipated Consequences}

In 1936, Robert Merton published his classic paper "The Unanticipated Consequences of Purposive Social Action" [5]. This was the first study to discuss, in a systematic fashion, unanticipated consequences. As the title states, Merton is interested in purposive social action, as opposed to behavior that does not involve a choice between various alternatives. He strongly stresses, however, that purposive action is not necessarily rational in an instrumental sense (that the actor always selects the most adequate means for the attainment of its end). Merton makes a number of important conceptual distinctions, both about the causes of unanticipated consequences and the character of these consequences. The four causes he finds-ignorance, error, the imperious immediacy of interest, and self-defeating predictions-make it clear that unanticipated consequences cannot be avoided altogether, but are possible to reduce. They can occur because the actor lacks the time and energy to reflect over possible outcomes of an action; because the actor has a distorted understanding of the situation and the probable chain of events; because the actor only sees the short-term, intended consequences, and not the later or different consequences of the action taken; and because predictions about human actions may become new elements in the concrete situation, and thus, change the outcome of the initial course of action. Merton is interested not only in the causes of unanticipated consequences, however, but also the character of these consequences. 
Unanticipated consequences are those effects of an action that were not originally aimed for. Even if Merton restricts his discussion to actions taken by particular actors (individuals or organizations), he has a broad focus on consequences, including the consequences for other persons than the actors in question.

In analyzing unanticipated consequences, Merton also raises two methodological problems. The first is the question of causal imputation: What consequences can justifiably be attributed to a certain action? The second is the problem of ascertaining the actual purpose of a given action, given that judging the reliability of post facto declarations of intention is notoriously complicated. However, as Merton states, it is less difficult to trace intentions with formal organizations than with individuals, because organizations have explicit procedures and statements of purpose.

Merton's analysis makes a substantial contribution to the understanding of unintended consequences, but it needs to be further developed. Many later contributions (see, e.g., [6-8]) have stressed that there is a conflation of unanticipated and unintended consequences, showing that much of the literature of today treats them as synonymous. Another conceptual conflation is that, in popular speech, unintended consequences are often associated with unwelcome consequences, contrary to Merton's (and others') view [6,8]. The term "unintended consequences" only refers to the results of behavior undertaken for another purpose, and has nothing to do with whether they are evaluated as good or bad, or are foreseen or unanticipated. To further develop its conceptual meaning, in the following, we will show how findings from risk sociology can refine our understanding of unintended consequences

\subsection{The Contribution of Risk Sociology}

The fundamental objectives of risk analysis are to anticipate potential harm, to average these events over time and space, and to use relative frequencies (observed or modeled) as a means to specify probabilities [9] (p. 53). In this sense, risk analysis aims to dissolve the phenomenon of undesirable unanticipated consequences; all severe negative consequences should be known and made part of the risk calculus. Risk analysis aims to reveal consequences that otherwise would have been unanticipated, and therefore, unavoidable; that is, it aims to replace unanticipated consequences by unintended consequences (known, but not aimed for). This does not mean that these negative consequences will always be avoided, only that they should be known and hence be possible to act upon.

Risk analysis assumes that the likelihood and potential negative consequences of a proposed action can be known, at least in principle. However due to the complexity and contingency of situations, this is rarely the case, and if risk assessment ignores this fact, it will produce an illusion of controllable, probabilistic, and deterministic processes [10]. To avoid an overly simplistic view of risk and risk analysis, the following key distinctions have been suggested: risk (knowing the odds), uncertainty (not knowing the odds, but maybe knowing the relevant parameters), ignorance (not knowing what we don't know), indeterminacy (causal chains or open networks) [10]. Our point is, therefore, not to claim that risk analysis makes it possible to dissolve complexity and eliminate unanticipated consequences, but only that in society today, there is a belief in the possibility of revealing, in advance, the major outcomes of an action, and that efforts are made to do so. In this sense, risk analysis creates space for action, as it makes the future amenable to calculation, deliberation, and decision-making [11,12]. Risk management concerns exactly this: to generate and evaluate options, select one, and then monitor its implementation $[4,13]$. This means that risk analysis does not necessarily lead to stopping or reducing a particular activity, but instead, could lead to the development of organizational capacities for handling disasters and/or the development of organizational and societal resilience. The contribution of risk sociology to risk research is its emphasis in how risks are always situated in a social context and are necessarily connected to actors' activities [14]. It contributes at least four aspects that improve the analysis of unintended consequences, namely, differentiation, recognizability, responsibility, and framing. 
Differentiation: A crucial contribution of risk sociology is that risks always have different implications for different contexts, interests, and categories [14,15]. Actors have various cultural belongings and structural positions which cause them to understand and evaluate phenomena differently, and therefore, also to act differently. This has long been known by risk researchers in the behavioral and social sciences, and numerous studies have shown how different groups and individuals perceive risks $[4,16]$. Whereas, earlier research explained lay people's risk evaluations with reference to social and contextual factors, resulting in a contrast between lay people's subjective risk perception and experts' objective risk assessment; later research stresses that all risk assessments-also those made by experts-are contextually generated $[12,14]$.

Developing sociological knowledge on risks therefore implies contextualizing risks; that is, understanding them as a result of how actors, located in specific social settings, understand and manage certain phenomena [17]. Basically, a situation or event is characterized by risk when something that human beings value is at stake, and the outcome is uncertain [18] (p. 17). When it comes to risk, however, there are always winners and losers, due to the differing social risk positions of various parties. Negative consequences are unevenly distributed; many times, the social location of decision-making is decoupled from the places and times where others become the objects of possible physical, social, and economic injuries [19] (p. 161).

When analyzing unintended consequences, it is therefore always important to discuss the social, spatial, and temporal dimensions of the action to be undertaken. An unintended consequence may be positive and negative at the same time, as its character (positive or negative, major or minor) may differ for different groups, social categories (class, gender, race/identity), geographical regions, and time scales (long or short term) (cf. [20]). Thus, the questions for whom, where, and when, are important to consider when analyzing unintended consequences. This is also related to the normative question; the severity of unintended consequences has to be evaluated from a normative standpoint, and this standpoint is often not articulated, and may also be dependent on the evaluator's risk position. A possible unintended consequence may be seen as minor by the actor that takes the decision, but for the person, organization, or community that is exposed to it, it may appear to be anything but minor.

Recognizability: Risk analysis points to a central difference between unanticipated and unintended consequences; the unanticipated is never known beforehand, whereas unintended consequences may very well be foreseen, but the action is taken nonetheless. The reason for this is that these possible consequences may be recognized, but be evaluated as improbable or unlikely to occur (e.g., a nuclear reactor accident) or they may be seen as probable, but having minor consequences in relation to the benefits that result from the action (e.g., traffic injuries compared to the benefits of mobility). Another category of unintended consequences comprises effects that are known and have high probability and substantial negative consequences; in such cases, the action may nevertheless be chosen, due to the temporal delay between cause and effect (e.g., smoking, with a temporal distance between the subjective benefits of smoking and future negative health effects). Also, there may be known unintended consequences that are not (only) delayed in time, but are distributed in space, affecting other people than the actor, which can lead to the action being chosen.

Merton [5] (p. 895) stresses that unanticipated consequences are a result of the interplay between purposive action and its context (the situation of action), but nevertheless, he restricts his focus to actions viewed in isolation. Even if this is understandable for analytical reasons, this is a substantial shortcoming because the increasing complexity of society has also made many consequences inaccessible from the position of the individual. Technical progress and global interconnectedness have made it difficult to figure out all the consequences of a specific action [21-23]. Also, many consequences are not perceptible to individuals, and discerning them requires expert systems that can calculate aggregated effects. This means that the knowledge about consequences is unevenly distributed in society. And, even in cases where this knowledge is widely distributed in society, there is a tension between individual and collective rationality (climate change is often referred to as involving this kind 
of problem). Thus, purposive action may result in unintended consequences that are hard to perceive from an actor perspective.

Responsibilization: Whereas the increased focus on risk management practices may result in some unintended consequences being avoided, in those cases where unintended consequences do appear, it may result in strong criticism being directed towards the organization that caused the consequences. Not least in cases of severe regulatory failure, strong criticism is often directed at the political, regulatory, and operational organizations that are seen as responsible and accountable for it [11,24]. Unintended consequence may be of indirect kinds that go far beyond the direct consequences of an activity or event, such as regulatory changes, new conditions for insurance, consumer boycotts of a product, decreased institutional confidence, and social stigma [25]. Risk researchers even claim that indirect ("secondary") risk has now become the main object of organizations' risk management strategies, for the reason that organizations have to govern their reputations [20,26] and avoid blame [27-29]. When severe consequences emerge, questions of responsibility are raised, something for which organizations have to be prepared $[30,31]$. This is the reason why organizations have developed risk communication programs and activities for managing public opinion and perceptions [27,32], and may also develop strategies for creating a situation of "organizational irresponsibility" [33], where it is difficult to hold any particular individual or organization accountable for a disaster.

Framings: A frame brings order to reality [34,35]. Getting other organizations and people to see the world according to a preferred frame is a way to generate legitimacy for ideas about what should be viewed as serious risks and appropriate responses to them [36]. A particular frame may recognize certain risks, but see them as either unlikely to appear or marginal (likely to appear but with minor negative impact). (That said, disasters can of course open up spaces for questioning dominant frames and presenting alternative ones. Disasters may also serve as formative events, providing learning opportunities and initiating policy change [37-39].) For Beck, the emergence of risk society invalidates the risk contract of industrial society; the new character of risk makes it impossible either to compensate victims or to govern the risks. What Beck does, here, is to suggest an alternative framing of industrial progress and risks, one that shifts the spotlight from industrial goods (material wealth) to industrial bads (environmental risks), but also provides a new narrative for societal development; society is currently developing towards catastrophe, not because of the shortcomings of technical progress and rationalization, but because of their successes. Thus, what was understood as a set of legitimate activities (industrial progress) is now on shaky ground because of a changed interpretation of the character of unintended consequences of these activities.

To give another example of the importance of framing, a disaster can be framed as a unique event, destructive for the locality and region in which it occurred, but with no further consequences. However, it can also be framed as a fundamental characteristic of the uncertainty associated with a particular sector or industrial activity, and thus, as a sign of a global risk. Disasters as the Deepwater Horizon drilling rig explosion in the Gulf of Mexico in 2010, and the Fukushima Daiichi nuclear disaster in 2011, are examples of this; some organizations and sectors (not least, nuclear power and oil companies) claim that they were isolated events that will never be repeated, whereas others (not least environmental organizations) claim that these disasters reveal general risks associated with nuclear power and deep drilling for oil, no matter where they are located. Thus, how an activity or event is framed is central to what reactions and responses it elicits. A striking example of this is global terrorism; it is not the single act (a particular attack with its direct consequences) but the meaning ascribed to it- the global staging of it - that shapes its consequences and makes it a global danger [19] (p. 10-11). In this way, the previous central demarcation between risk and risk perception now collapses.

However, as described above, frames matter, and they precede the evaluation of risks. A frame makes some ways of apprehending a phenomenon possible, while at the same time, eliminating others. Frames are fundamental for the determination and evaluation of a disaster's causes and consequences, and also for the allocation of responsibility [30,40]. In many cases, they are implicit and naturalized; a frame is taken for granted by the organizations and people involved, and therefore, is not 
made the subject of discussion. Labeling negative consequences as "unanticipated," "unintended," "secondary," or "side effects", means attaching particular meanings to these consequences. Due to different framings-which may be connected to an actor's risk position-unintended consequences can be seen as positive or negative, major or minor.

\section{Materials and Methods}

\subsection{The Empirical Study}

As described above, the adoption of a language of risk makes it harder to legitimize unintended consequences, because claims can be raised that they should have been foreseen. In cases where decisions lead to severe negative consequences—of which disasters are prime examples—questions can be raised about why an activity that causes such detrimental consequences has been permitted, why no preventive measures have been taken, or why capacity has not been developed to mitigate these consequences. As Kai Erikson [41] finds in his study of communities that have experienced disasters and developed a traumatic syndrome, it is not the size of a disaster that matters but its character; disasters that are caused by (other) human beings cause a feeling of injury and vulnerability from which it is difficult to recover, and which result in a changed sense of self, a changed way of relating to others, and a changed world view (namely that the institutions that are in charge cannot be relied upon). Thus, strong legitimation conflicts may occur, involving demands to take responsibility, change regulations, and economically compensate those affected.

In this section, we will analyze a particular disaster, a large forest fire, as $<$ way to develop an understanding of unintended consequences, in particular, in relation to human-made disasters. This case has certain characteristics that make it relevant to study; it was human-caused and had unintended and severe consequences, and it can, therefore, be claimed that that the risk of causing a large-scale forest fire should have been anticipated, and therefore avoided. Obviously, it is not possible to make statistical generalizations from this study, and the empirical results are not transferable to other contexts than the one studied here. Nevertheless, it is possible to derive more general knowledge from a single case study [42,43], for instance, about how the context and framing of a disaster heavily affect the evaluation of its consequences.

After briefly describing the events, we analyze how the people directly affected by the disaster evaluate it, in particular, how they view the causes and consequences of the disasters, and to what extent and to which organization they ascribe accountability for the disaster. We will use the categories cause, recognizability, responsibility, differentiation, and framings, to analyze the views of the affected people. We do not claim that their evaluation of the disaster is the proper one, but only that it is an important one because they are directly affected by the disaster. Disasters always involve multiple contexts, actors, victims, and audiences $[20,23,28]$. Organizations involved in the acute phase or recovery phase of a disaster always have to consider this; satisfying one group may involve upsetting another. However, for our study of unintended consequences, it is most relevant to select those primarily affected by the disaster.

A brief description of the wider context of this case is needed. In Sweden, approximately $50 \%$ of productive forest land is owned by individuals, $30 \%$ is owned by private companies, and $20 \%$ is publicly owned (generally by state-owned companies) [44]. Individually held forestland generally takes the form of small parcels. A main component of Swedish forest policy is that the goal of preserving the environment should be given the same priority as the goal of producing woody biomass $[45,46]$. Simultaneously, forest owners have considerable latitude when it comes to how to manage their forest. This is often summarized in the governing principle "freedom with responsibility", which means that a set of rules should specify the principles for forest use, while the Government acts by providing information, advice, and recommendations [30,47]. 


\subsection{The Fire Disaster}

In the summer of 2014, Sweden experienced the largest forest fire in its modern history, covering an area of 14,000 hectares in four municipalities [40,48]. A large forest company had hired a local entrepreneur to perform subsoiling, and on 31 July, a forest vehicle ignited a fire. The weather had been extremely hot and it had not rained for weeks, which caused the fire to spread rapidly; two fire departments (from different municipalities) had to separately fight it. However, on the fifth day, the fire went completely out of control, spreading from 2800 to 13,000 hectares, and for the first time, it was perceived by the authorities as a major crisis. This led to a reorganization of the operations, involving governmental agencies as well as fire and rescue services from other parts of Sweden, as well as firefighting planes from France and Italy that waterbombed the fire. Eight days after its start, the wildfire was put under control (most of the aboveground fire was put out), and six weeks later (September 11th), it was formally declared as extinguished.

In total, 2300 people - police officers, soldiers, firefighters, forestry workers and volunteers-were mobilized to fight the fire, and evacuate people and animals. The damage from the fire was considerable: it caused one fatality; over 1000 people and 1700 animals (cattle and sheep) were evacuated; 71 buildings were damaged or destroyed; 15,000 hectares were burned, and 1.4 million cubic meters of timber was damaged; three nature reserves and ten habitat protection areas and nature conservation agreements were affected. The total cost of the fire is estimated to at least 100 million euros $[49,50]$. The burned area is owned by approximately 100 small-scale private landowners, and a handful of large forest companies and organizations. In spring 2015, almost half of the area (6400 ha) was declared a nature reserve, with the state offering either economic compensation or a new forest property in the vicinity for those owning forest in the newly established nature reserve. Afterwards, several investigations found that the spread of the fire could have been drastically curtailed if the fire departments and the crisis management activities had been better organized and coordinated [51]. Although, from a national perspective, the burned volume only amounts to about $2-3 \%$ of the annual gross volume of fellings, from a local perspective and for those directly affected, the fire had severe consequences. Because the disaster, according to governmental investigations, was human-made, avoidable, and affected local residents, it is of interest to investigate how the local residents experienced and interpret the fire.

\subsection{The Empirical Material}

A postal survey was distributed by Statistics Sweden to all adults (18 years or older) directly affected by the forest fire. Directly affected persons comprise four categories: permanent residents; summer cottagers; forest owners; and evacuees (both those who, in fact, were evacuated, and those asked by public authorities to be prepared to evacuate). This sample consists of 960 individuals, and the response rate was $78 \%$ (746 respondents). The survey is relatively comprehensive, with 133 questions in total. The themes covered in the survey concerned both general views on forest fires in Sweden and views on the 2014 wildfire in particular, such as causes of the fire, ecological, economic, and social consequences of the fire, evaluation of the work of involved organizations, and whether respondents' trust in these organizations had changed because of the fire. Descriptive and bivariate analysis has been employed using SPSS software. This study is a census of all individuals directly affected by the fire; the results should, therefore, only be generalized to this population of directly affected individuals.

\section{Results}

\subsection{Causes}

Unintended consequences are deeply associated with human action; if no human decision or action can be discerned behind a consequence, it does not fall under the category of unintended consequences. As Table 1 shows, the respondents consider the forest fire disaster to be man-made or at least partly man-made, both in terms of origin and severity. At the same time, a majority of the 
respondents acknowledge the role played by the extreme weather conditions, stating that there was little to set against the fire. A reasonable interpretation is that the respondents acknowledge that once the fire had reached a certain magnitude, there was little that could be done. The fact that most of the respondents point to the human origin of the fire raises the question of who or what to blame for the disaster. The respondents give a complex picture, with municipalities, fire departments, individual mistakes, and forestry practices being seen as the most important causes.

Table 1. Causes of the disaster.

\begin{tabular}{|c|c|c|c|c|c|}
\hline Statement & Agree \% & Partly Agree \% & Disagree \% & $\begin{array}{l}\text { Don't Know or } \\
\text { No Answer \% }\end{array}$ & Sum $\%$ \\
\hline $\begin{array}{l}\text { The forest fire could have been avoided } \\
\text { completely. }\end{array}$ & 66.7 & 16.0 & 10.7 & 6.6 & 100 \\
\hline $\begin{array}{l}\text { It could have been avoided that the } \\
\text { forest fire became so severe. }\end{array}$ & 81.1 & 10.9 & 4.5 & 3.5 & 100 \\
\hline $\begin{array}{l}\text { Due to weather conditions, there was } \\
\text { little to set against the fire. }\end{array}$ & 64.3 & 23.2 & 9.7 & 2.8 & 100 \\
\hline $\begin{array}{l}\text { It was forest company activities that } \\
\text { started the fire. }\end{array}$ & 74.7 & 8.1 & 6.5 & 10.7 & 100 \\
\hline $\begin{array}{l}\text { The forest fire became so severe because } \\
\text { of Swedish forestry practices in general. } \\
\text { The forest fire became so severe }\end{array}$ & 28.8 & 26.3 & 27.2 & 17.7 & 100 \\
\hline $\begin{array}{l}\text { because of large deficiencies in the } \\
\text { fire department. }\end{array}$ & 59.6 & 21.1 & 11.9 & 7.4 & 100 \\
\hline $\begin{array}{l}\text { The forest fire became so severe } \\
\text { because of large deficiencies in the } \\
\text { coordination between municipalities. }\end{array}$ & 65.8 & 15.4 & 9.6 & 9.2 & 100 \\
\hline $\begin{array}{l}\text { The forest fire became so severe because } \\
\text { of large mistakes by individuals. }\end{array}$ & 37.0 & 20.0 & 24.6 & 18.4 & 100 \\
\hline
\end{tabular}

\subsection{Recognizability}

Risk thinking means that there should not be any severe unanticipated consequences, because risk analysis should reveal, beforehand, the potential outcomes associated with different options. However, an action may be chosen despite the knowledge that it may result in a negative outcome. The reason for this is either that the probability of an outcome is believed to be low, or that the consequences are seen as minor compared to the benefits of the action taken. Annually, there are some 1000 small-scale forest fires in Sweden, and forest operators are prepared to handle situations where their operations ignite fires (e.g., by having fire extinguishers at hand). In this case, there was extreme weather, but nevertheless, the forest company and the forest operator believed that it would be possible to prevent a small fire from growing into a wildfire. Similarly, the fire department initially believed, despite the extreme weather, that the fire was under control, but the arrival of strong winds suddenly changed the situation dramatically. As stressed above, the majority of the respondents believe that the forest fire could have been avoided completely.

An indication of where the respondents place blame for the disastrous outcome of the forest fire is given by how they evaluate various organizations' performances during the fire. It is striking that the fire department is one of the organizations that the respondents viewed as having done a good or very good job; only volunteer organizations are considered to have done a better job. (As shown in Table 2, the proportion of respondents who answered that they don't know is very high for most questions, which makes it difficult to estimate how critical the respondents, in fact, are. However, the volunteer organization and the fire department are exceptions to this pattern. One reason for this may be that the respondents probably met representatives of these organizations during the firefighting and post-fire work, making it easier for them to evaluate their performance.) Thus, despite being attributed a causal role in the fire disaster, the fire department's work is, nevertheless, positively evaluated (see Table 3 for a cross-tabulation). As Table 2 shows, forest companies are the only actor that is not evaluated mainly positively. However, almost $40 \%$ of the respondents chose to not evaluate the forest companies at all (either by not answering the question or by choosing the option "don't know"), which indicates 
that there is no strong criticism towards it. If the forest companies were framed as responsible for the disaster, respondents would arguably evaluate them negatively, rather than have no opinion. Thus, there is no strong attribution of blame towards any organization, and even towards the forest companies, there are mixed views and no clear attribution of blame.

Table 2. Evaluation of efforts during the disaster.

\begin{tabular}{|c|c|c|c|c|c|}
\hline Statement & $\begin{array}{l}\text { Very Good or } \\
\text { Good Job \% }\end{array}$ & $\begin{array}{l}\text { Neither Good } \\
\text { nor Bad \% }\end{array}$ & $\begin{array}{l}\text { Very Bad or } \\
\text { Bad Job \% }\end{array}$ & $\begin{array}{l}\text { Don't Know or } \\
\text { No Answer }\end{array}$ & Sum $\%$ \\
\hline $\begin{array}{l}\text { Did volunteer organizations do a good } \\
\text { or a bad job during the fire? }\end{array}$ & 93.1 & 1.3 & 0.8 & 4.8 & 100 \\
\hline $\begin{array}{l}\text { Did the Swedish Forest Agency do a } \\
\text { good or a bad job during the fire? }\end{array}$ & 15.7 & 22.5 & 8.4 & 53.4 & 100 \\
\hline $\begin{array}{l}\text { Did the County Administrative Board } \\
\text { do a good or a bad job during the fire? } \\
\text { Did the Swedish Civil Contingencies }\end{array}$ & 53.0 & 17.8 & 10.9 & 18.3 & 100 \\
\hline $\begin{array}{l}\text { Agency (MSB) do a good or a bad job } \\
\text { during the fire? }\end{array}$ & 42.4 & 16.3 & 12.4 & 28.9 & 100 \\
\hline $\begin{array}{l}\text { Did the fire departments do a good or a } \\
\text { bad job during the fire? }\end{array}$ & 71.3 & 7.5 & 15.7 & 5.5 & 100 \\
\hline $\begin{array}{l}\text { Did the forest companies do a good or a } \\
\text { bad job during the fire? }\end{array}$ & 17.9 & 25.0 & 19.0 & 38.1 & 100 \\
\hline $\begin{array}{c}\text { Did the municipalities do a good or a } \\
\text { bad job during the fire? }\end{array}$ & 43.6 & 20.1 & 25.7 & 10.6 & 100 \\
\hline
\end{tabular}

Table 3. Cross-tabulation of the views on the forest department.

\begin{tabular}{cccccc}
\hline \multirow{2}{*}{ Statement } & & \multicolumn{2}{c}{$\begin{array}{c}\text { The forest fire became so severe because of large } \\
\text { deficiencies in the fire department }\end{array}$} & \multirow{2}{*}{ Total } \\
\cline { 2 - 5 } & & Agree & $\begin{array}{c}\text { Partly agree } \\
\text { and disagree }\end{array}$ & Disagree & \\
\hline $\begin{array}{c}\text { Did the fire } \\
\text { departments do a } \\
\text { good or a bad job } \\
\text { during the fire? }\end{array}$ & Good job & $62.5 \%$ & $94.1 \%$ & $96.6 \%$ & $74,2 \%$ \\
\cline { 2 - 5 } & Neither & $11.1 \%$ & $3.3 \%$ & $2.3 \%$ & $8.1 \%$ \\
\hline Total & Bad job & $26.4 \%$ & $2.6 \%$ & $1.1 \%$ & $17.6 \%$ \\
\hline
\end{tabular}

\subsection{Differentiation}

As seen above, there are rather few very critical voices, despite the fact that the wildfire is seen as human-caused, that a handful of organizations are seen as causing it, and that all respondents have been exposed to the fire. This result seems to contradict what we have conceptually elaborated above - that due to the existence of different social risk positions, there are always winners and losers in risk issues. However, a closer look at the respondents' views and evaluations of the disasters make it understandable. Turning to what the respondents see as the greatest loss for them personally, the most common answer is that the fire has not caused them any personal loss at all, followed by lost opportunities to pick mushrooms or berries, or to hunt or fish in the area, loss of closeness to experiences of nature, and that the burned forest is horrible to look at (see Table 4). Of importance is that very few state that their greatest personal loss was of economic character, and even if about one in ten are worried (psychological stress, sense of insecurity, and grief), the majority attach no strong loss to the disaster. This may be an important reason for seeing a particular organization as responsible for the disaster but not putting any blame on them. 
Table 4. What is the greatest loss for you personally as a result of the fire?

\begin{tabular}{|c|c|c|c|}
\hline Statement & Percent & Count & Accum. Percent \\
\hline $\begin{array}{l}\text { The forest fire has not personally caused } \\
\text { me any losses }\end{array}$ & 29.2 & 218 & 29.2 \\
\hline $\begin{array}{l}\text { I am not able to pick mushrooms or } \\
\text { berries anymore, or to fish or hunt in the } \\
\text { area }\end{array}$ & 18.2 & 135 & 47.4 \\
\hline $\begin{array}{l}\text { The opportunity to have experiences } \\
\text { close to nature is gone }\end{array}$ & 15.4 & 115 & 62.8 \\
\hline $\begin{array}{c}\text { The burned forest is horrible to look } \\
\text { at/the forest is gone }\end{array}$ & 11.8 & 88 & 74.6 \\
\hline $\begin{array}{c}\text { Worry about new fires/Psychological } \\
\text { problems/PTSD/Grief/Lasting sense of } \\
\text { insecurity }\end{array}$ & 10.8 & 81 & 85.4 \\
\hline Loss of economic value & 6.0 & 45 & 91.4 \\
\hline Other & 2.7 & 20 & 94.1 \\
\hline Don't know/No answer & 5.9 & 44 & 100 \\
\hline Total & 100 & 746 & \\
\hline
\end{tabular}

There are two further aspects which may have contributed to respondents' view of the fire. First, the respondents attached a number of general positive consequences to the fire (Table 5). Obviously, the respondents tend to perceive forest fires as a negative event. However, it is noteworthy that more than a third agree or partly agree with the statement that forest fires are a good thing as long as people, animals, and buildings are protected. As Table 5 shows, most of the respondents also associated a number of positive consequences with the forest fire.

Table 5. Positive unintended consequences.

\begin{tabular}{cccccc}
\hline Statement & Agree \% & Partly Agree \% & Disagree \% & DK/NA \% & Sum \% \\
\hline $\begin{array}{c}\text { Forest fires are a good thing, as } \\
\text { long as people, animals, and } \\
\text { buildings are protected. }\end{array}$ & 11.1 & 25.5 & 50.0 & 13.4 & 100 \\
$\begin{array}{c}\text { In the long term, the forest fire } \\
\text { will result in greater diversity of } \\
\text { species in Västmanland. }\end{array}$ & 55.0 & 23.5 & 9.5 & 12.0 & 100 \\
$\begin{array}{c}10 \text { years from now, the fire } \\
\text { departments will be better as a } \\
\quad \text { result of the forest fire. }\end{array}$ & 44.6 & 30.2 & 16.0 & 9.2 & 100 \\
$\begin{array}{c}\text { The municipalities will be better } \\
\text { prepared to handle disasters as a } \\
\text { result of the forest fire. }\end{array}$ & 40.1 & 31.0 & 20.2 & 8.7 & 100 \\
$\begin{array}{c}10 \text { years from now, Swedish } \\
\text { forestry will be more fire resilient } \\
\text { as a result of the forest fire. }\end{array}$ & 30.0 & 34.9 & 20.0 & 15.1 & 100 \\
\hline
\end{tabular}

\subsection{Framing}

The above results are only partially expected from our discussion of unintended consequences. If disasters are seen as human-made and avoidable, it is reasonable to expect them to be followed by strong processes of responsibilization and blaming. However, as our analysis shows, this was not the case, and there are surprisingly few critical voices. An important reason for this result it that the respondents do not attribute any severe negative consequences for themselves, personally, to the disaster (see Table 4). Those that are mentioned, which are mainly recreational (such as loss of places to go berry-picking and fishing), seem to be less important than, or outweighed by, the positive consequences the respondents attribute to the disaster (see Table 5). In this sense, the disaster does not seem to have created any losers among the directly affected parties. An important reason for this is that forest fire insurance largely compensated the economic losses of the property owners. Seventy-five 
percent of the damaged forest was insured for forest fires, and the remaining part was mainly owned by one large-scale forest owner (less economically vulnerable than small-scale ones). In this sense, it appears to many people to be almost a "happy disaster"; a disaster which is originally seen as severe, but afterwards, is seen as mainly resulting in positive consequences. Important to note is that this does not mean that the fire disaster lacks negative long-term consequences, but only that these kinds of consequences are downplayed or left unarticulated by the respondents.

There are a number of factors that partly explain this result: the disaster is believed not to have involved any toxic substances with long-term health effects; it resulted in only one fatality; most forest owners were compensated by insurance companies; the fire occurred in a sparsely populated area; and those few permanent houses or summer cottages that were damaged were insured. However, this result cannot solely be explained by economic and structural factors; also important is how the disaster was framed. We will, in particular, stress one aspect: how the economic consequences were framed as only concerning local aspects.

Insurance covered much of the costs for the individual forest owners, thereby mitigating much of the economic consequences of the fire disaster. However, the disaster will result in higher insurance premiums for all Swedish forest owners, as the economic costs of the fire (estimated to 50 million euros) are distributed to a large number of insurance holders, and also are delayed in time (gradual increase of insurance premiums). Another factor is that a substantial share of the cost was covered by the state, and thereby was rendered invisible in much public discussion; the total cost for the fire (the emergency operations and the damages) is estimated to at least 100 million euros and the emergency operations were financed by the state and municipalities (i.e., through taxes). Furthermore, the Swedish state is striving to establish more nature reserves, and the fire made it possible to establish a new one. Almost half of the fire area (6400 ha) was made into a nature reserve, with the state offering either economic compensation or a new forest property in the vicinity for those owning forest in the newly established nature reserve. (The Swedish state owns about 100,000 ha of forest to use as "exchange property" when establishing nature reserves in privately-owned forest areas.) The establishment of a nature reserve was also welcomed by environmental organizations, which may also be a reason why there was so little social conflict in the aftermath. It is also interesting that more than half of the respondents agree that the fire is positive for biodiversity (see Table 5), which also shows that the positive long-term environmental effects are an important part of the framing of the disaster. That many respondents believe that the fire was good for biodiversity echoes what has been stated by the Forest Agency and distributed by media.

Thus, there were few reasons for those affected (local residents and local forest owners) to be critical, and the establishment of the nature reserve implied that other actors, such as environmental organizations and regulatory bodies (the Forest Agency, Environmental Protection Agency, and County Administrative Board) mainly saw the fire as resulting in positive consequences. Obviously, all actors agree that there is much to learn from this disaster (not least for the fire departments and crisis management authority) but that this particular fire disaster had strong positive environmental consequences and few negative ones. Thus, the disaster was framed as having had few negative outcomes and offering important learning opportunities. Therefore, despite its human-made character, little blame was directed towards organizations seen as responsible for the disaster.

What in the acute phase was seen as a disaster, an uncontrolled fire threatening life, health, private property, and environmental values, was, in the post-fire phase, redefined as almost a "happy disaster", a disaster with mainly positive consequences. With the help of nature (reduced wind and temperature), the fire was brought under control and finally extinguished, and by externalizing economic costs (through forest insurance as well as state support) and by protecting environmental values through the establishment of a nature reserve in part of the burned area, many negative consequences were mitigated, at least on a local level, and some positive consequences were created. Thus, the fire disaster was reframed as a disaster with few negative consequences. 


\section{Discussion: The Dynamics of Unintended Consequences}

Like all case studies, this study has its limitations and advantages. The point made here is that even if the studied case has a unique character, it has also a number of common traits, making it meaningful to analyze in order to gain broader knowledge about how to understand unintended consequences, and the extent to which risk analysis deepens and problematizes this phenomenon. The discussion is structured in three parts, first, the studied case is introduced, then its contribution to our general understanding of unintended consequences is discussed, and finally, some general thoughts are presented about the extent to which extent risk thinking may dissolve, or at least problematize, unintended consequences, and with what implications.

\subsection{The Case}

The studied forest fire is open for multiple interpretations; in this study, we focus on how it was interpreted by those directly affected by it. An assumption is that they should be more critical in their evaluations of responsibility, and not accept any excuse that the fire was hard to anticipate and was not intended. The reason for this is that risk evaluation should precede action, which in this case, means that subsoiling activities should not have been undertaken because of the high probability that they would ignite a forest fire. With the spread of risk thinking in society, unanticipated consequences should be known beforehand (risk evaluation should make explicit major risks associated with different options, that is, the potential consequences of a different course of action and their likelihood). Obviously, this is not always the case; unanticipated and unintended consequences regularly occur in everyday life, as well as professional life. From a Mertonian perspective (see Section 2.1), the forest fire can be seen as caused mainly by imperious immediacy of interest (the forest operator and forest company's actions were guided by short-term and intended consequences, neglecting later and unintended ones), and perhaps also by ignorance (they did not allocate time and energy to reflect over possible outcomes).

Thus, the point made in this paper is not that risk thinking has put an end to the phenomenon of unintended consequences. In fact, contingency-that it is not possible to fully predict the consequences of human action-is a cornerstone of risk thinking [4,52]. Nevertheless, when a disaster occurs, the spread of risk thinking in society should make it harder for those who caused it to avoid responsibility by claiming that it was not possible to foresee, or at least, that it was unintended. The empirical study presented here provides an unexpected result: those directly affected have a less critical view of the organization that caused the fire and its responsibilities than those who conducted external investigations of the disaster. The public investigations stressed that the shortcomings of organizations, particularly the forest sector and the crisis management authorities, contributed to the fire growing out of control $[51,53,54]$. (The report by the Swedish government commission states that the prevailing weather conditions made subsoiling a dangerous practice, and points to the need to consider whether certain forest activities and operations should be subject to prohibition when there is high risk of forest fires. It also points to the forest sector's lack of systematic preventive work [54].) A major reason for the difference in viewpoint between the directly affected parties and the public investigations is probably that the disaster had few negative consequences for those directly affected. Research has found that differences in local responses are strongly dependent on the recovery phase, i.e., what happens in the aftermath of a disaster [41,55]. Whereas most property owners in the area were compensated by their insurance companies, the national insurance companies are now pursuing a litigation process to sue the forest company that caused the fire, demanding $25 \mathrm{M}$ euros (277 M SEK) to cover their payments to affected forest owners. Thus, not only costs, but also conflicts have, in this case, been transferred from local to national level, thereby creating a view of the forest fire as almost a "happy disaster." 


\subsection{What Is to Be Learned from This Case?}

What can this case contribute to our understanding of unintended consequences? In answering this question, we will stress four aspects in particular: that important spatial and temporal characteristics are attached to unintended consequences; that unintended consequences are dynamic and changing; that they can intentionally be acted upon; and that they raise important issues of accountability.

Firstly, as stressed in our theoretical elaboration, no event speaks for itself; events are always understood through particular frames. Framing processes are, therefore, crucial in the evaluation of unintended consequences. Worth noting is that that the temporal and spatial dimensions are important in guiding our attention and interpretation. As seen in our empirical case, economic consequences were mainly discussed on the local level (thereby concealing much of the economic costs), whereas the environmental consequences were located to both the local and national levels. The shaping of the temporal and spatial identity of a disaster is, therefore, pivotal when evaluating its consequences, and thus, also when developing responses.

Secondly, unintended consequences are dynamic and changing. The reason for this is that there is no simple causal relation between action and consequences, because the context in which the action takes place heavily influences what consequences it will bring about. Importantly, the context of an action is not easy to determine and demarcate; its consequences may travel over spatial and temporal distances, visit different contexts, and result in cascade effects [56]. Even if a risk calculus precedes the action taken, some uncertainty will most likely remain about the magnitude and character of its potential consequences. This opens up the possibility for actors to influence what consequences should be considered of major importance. Consequences of disasters are of different types: environmental, economic, and social. These consequences also have different characteristics: they can be geographically restricted or spread out; they can be of short or long duration; and they can be unevenly distributed from a social perspective. They can further be directly caused by the event itself, or result from the work to mitigate the disaster, as well as later efforts to recover from it. Some consequences are possible to affect directly, whereas others are more difficult to observe directly. Instead, information about them (not least, long-term consequences) is mediated by organizations such as media, governmental bodies, and companies, which amplify and attenuate different consequences of a disaster [25].

Thirdly, unintended consequences can be acted upon. Humans will never be able to fully predict future social development, because human predictions and new knowledge will change the course of development along the way [21]. Whereas Merton views this as a cause of unintended consequences [5] (p. 904), we will argue that the same kind of reasoning can be used to understand the shaping of action in the aftermath of unintended consequences. An unintended consequence-in our case, a fire disaster-creates possibilities for intentional action. Organizations and people facing this new unintended situation have to do something. Many times, disasters can be used functionally, as learning opportunities, resulting in such things as improved safety of industrial operations and strengthened crisis management. Unintended consequences may also open up a window of opportunity, where, for a short period, particular decisions and actions are made possible (in our empirical case, establishing a nature reserve) [57]. Thus, unintended consequences may intentionally be used to direct a course of development and shape the consequences of a disaster, and become part of the framing process that guides how organizations and people evaluate it.

Fourthly, the fact that consequences are dynamic and difficult to completely know also raises the analytical problem of causation and accountability; to what extent should a single action-such as a forestry operation or a badly organized firefighting operation-be attributed to consequences that are partly a result of other factors? How should one navigate between a conception of individualized responsibility, that reinforces a scapegoat society, and a conception of organized irresponsibility, where no one can be held accountable? Unintended consequences may be of different kinds, and may be evaluated differently depending their social, temporal, and spatial characteristics, as well as the 
evaluator's own position, interest, and stake in the process. It is, therefore, important to recognize affected persons' understanding and evaluation of a disaster, but not in an unrestricted way. There are structures, causes, and consequences that may not be considered or are downplayed in the evaluation made by the affected parties, which means that disasters may be painted in either too dark or too bright colors.

\subsection{Risk Thinking and Responsibilization}

The overall question in this article is whether the spread of risk thinking implies that it will become harder to legitimate a human-made disaster with reference to it having been unintended. As stressed at the beginning, unintended consequences are not necessarily of negative character. Even in the case of environmental disasters, these phenomena should not only be painted in gloomy colors. Disasters can also result in positive consequences; an ambitious recovery effort may compensate damages, provide new opportunities for local development, and strengthen community resilience. Disasters may also be functional for the wider society, providing learning opportunities and initiating regulatory changes. But, this depends on how a disaster is framed and evaluated. The contribution of risk sociology is its stress on the fact that risks are always situated in a social context, and are necessarily connected to actors' activities. This means that alongside the work of combating a disaster or mitigating its direct consequences, there is often an ongoing effort to understand the disaster and to spread this understanding in society. If it is framed as an environmental disaster, its human causation may lead to demands to allocate responsibility and change practices. But, if it is framed as a disaster with few visible and long-term negative consequences, it will probably result in fewer critical voices and demands for accountability and changes in practices. In this sense, an overly positive framing may pave the way for a situation of "organized irresponsibility," where there is no need to figure out why the disaster could happen, and who to hold accountable. In such cases, policymakers, regulatory bodies, or operational companies may get away with stating that the consequences were "unintended."

To conclude, risk thinking shows that it should be hard to legitimate a disaster by claiming that it was unintended, even not foreseen. At the same time, risk sociology shows that there is a complex dynamic between an environmental disaster, our understanding of it, and our action upon it, making the evaluation of a disaster and its consequences a process with uncertain outcome.

Author Contributions: R.L. and D.S. has constructed the survey; D.S. analyzed the data from the survey; R.L. developed the theoretical framework and research questions, performed the analysis, and wrote the first draft of the paper. Both authors reviewed the final draft of the article before submission.

Funding: This research was funded by Swedish Research Council Formas, project Risk governance, legitimacy and social learning in the handling of the forest fire in Västmanland [211-2014-1875].

Conflicts of Interest: The authors declare no conflict of interest.

\section{References}

1. Beck, U. Risk Society. Towards a New Modernity; Sage Publications: London, UK, 1992.

2. Power, M. The Risk Management of Everything: Rethinking the Politics of Uncertainty; Demos: London, UK, 2004.

3. Giddens, A. Runaway World. How Globalization is Reshaping our Lives; Routledge: New York, NY, USA, 1999.

4. Renn, O. Risk Governance. Coping with Uncertainty in a Complex World; Earthscan: London, UK, 2008.

5. Merton, R.K. The unanticipated consequences of purposive social action. Am. Sociol. Rev. 1936, 1, 894-904; reprinted as "Unanticipated consequences of social action". In Sociological Ambivalence and Other Essays; The Free Press: New York, NY, USA, 1976; pp. 145-155.

6. Baert, P. Unintended consequences: A typology and examples. Int. Sociol. 1991, 6, 201-210. [CrossRef]

7. Boudon, R. The Unintended Consequences of Social Action; Macmillan: London, UK, 1982.

8. Zwart, F. Unintended but not unanticipated consequences. Theory Soc. 2015, 44, 283-297. [CrossRef]

9. Renn, O. Three decades of risk research: Accomplishments and new challenges. J. Risk Res. 1998, 1, 49-71. [CrossRef] 
10. Wynne, B. Uncertainty and environmental learning: Reconceiving science and policy in the preventive paradigm. Glob. Environ. Chang. 1992, 2, 111-127. [CrossRef]

11. Hood, C.; Rothstein, H.; Baldwin, R. The Government of Risk. Understanding Risk Regulation Regimes; Oxford University Press: Oxford, UK, 2001.

12. Wynne, B. Risk as globalizing 'democratic' discourse? Framing subjects and citizens. In Science and Citizens. Globalization and the Challenge of Engagement; Leach, M., Scoones, I., Wynne, B., Eds.; ZED Books: London, UK, 2005; pp. 66-82.

13. Amendola, A. Recent paradigms for risk informed decision making. Saf. Sci. 2001, 40, 17-30. [CrossRef]

14. Lidskog, R.; Sundqvist, G. The sociology of risk. In Essentials of Risk Theory; Roeser, S., Hillerbrand, R., Sandin, P., Peterson, M., Eds.; Springer: New York, NY, USA, 2013; pp. 75-105.

15. Lupton, D. Risk, 2nd ed.; Routledge: London, UK, 2013.

16. Taylor-Gooby, P.; Zinn, J. Risk in Social Sciences; Oxford University Press: Oxford, UK, 2006.

17. Lidskog, R.; Sjödin, D. Risk governance through professional expertise. Forestry consultants' handling of uncertainties after a storm disaster. J. Risk Res. 2016, 19, 1275-1290. [CrossRef]

18. Jaeger, C.C.; Renn, O.; Rosa, E.A.; Webler, T. Risk, Uncertainty and Rational Action; Earthscan: London, UK, 2001.

19. Beck, U. World at Risk; Polity Press: Cambridge, UK, 2009.

20. Carpenter, D.P.; Krause, G.A. Reputation and Public Administration. Public Adm. Rev. 2012, 72, $26-32$. [CrossRef]

21. Giddens, A. The Consequences of Modernity; Polity Press in association with Blackwell: Cambridge, UK, 1990.

22. Koehn, D. Living With the Dragon: Thinking and Acting Ethically in a World of Unintended Consequences; Routledge: London, UK, 2010.

23. Swee, H.; Hrdličková, Z. Living with Disasters: Perspectives on the (Re-)Production of Knowledge. Nat. Cult. 2017, 17, 1-17. [CrossRef]

24. Lidskog, R.; Uggla, Y.; Soneryd, L. Making transboundary risks governable: Reducing complexity, constructing identities and ascribing capabilities. Ambio 2011, 40, 111-120. [CrossRef] [PubMed]

25. Pidgeon, N.; Kasperson, R.E.; Slovic, P. (Eds.) Social Amplification of Risk; Cambridge University Press: Cambridge, UK, 2003.

26. Power, M. Organized Uncertainty. Designing a World of Risk Management; Oxford University Press: Oxford, UK, 2007.

27. Gouldson, A.; Lidskog, R.; Wester-Herber, M. The battle for hearts and minds. Evolutions in organisational approaches to environmental risk communication. Environ. Plan. C 2007, 25, 56-72. [CrossRef]

28. Hood, C. The Blame Game: Spin, Bureaucracy, and Self-preservation in Government; Princeton University Press: Princeton, NJ, USA, 2011.

29. Howlett, M. The lessons of failure: learning and blame avoidance in public policy-making. Int. Political Sci. Rev. 2012, 33, 539-555. [CrossRef]

30. Löfmarck, E.; Uggla, Y.; Lidskog, R. Freedom with what? Interpretations of "responsibility" in Swedish forestry practice. Forest Policy Econ. 2017, 75, 34-50. [CrossRef]

31. Soneryd, L.; Uggla, Y. Green governmentality and responsibilization: New forms of governance and responses to 'consumer responsibility'. Environ. Polit. 2015, 24, 913-931. [CrossRef]

32. Lidskog, R. Public at risk or public as risk. Regulating nature by managing people. Soc. Nat. Resour. 2016, 29, 284-298. [CrossRef]

33. Beck, U. Ecological Politics in an Age of Risk; Polity: Cambridge, UK, 1995.

34. Fischer, F. Reframing Public Policy. Discursive Politics and Deliberative Practices; Oxford University Press: Oxford, UK, 2003.

35. Schön, D.A.; Rein, M. Frame Reflection. Toward the Resolution of Intractable Policy Controversies; Basic Books: New York, NY, USA, 1994.

36. Weick, KE.; Sutcliffe, K.M.; Obstfeld, D. Organizing and the process of sensemaking. In Making Sense of the Organization. The Impermanent Organization; Wiley: Chichester, UK, 2009; Volume 2, pp. 131-152.

37. Birkland, TA. Lessons of Disaster. Policy Change after Catastrophic Events; Georgetown University Press: Washington, DC, USA, 2007.

38. Kingdon, J.W. Agendas, Alternatives, and Public Policies; Little Brown: Boston, MA, USA, 1984. 
39. Lidskog, R.; Sjödin, D. Time, knowledge, and risk: Decision making in the aftermath of storm disasters. Int. J. Mass Emerg. Disasters 2015, 33, 341-359.

40. Lidskog, R.; Sjödin, D. Extreme events and climate change. The post-disasters dynamics of forest fires and forest storms in Sweden. Scand. J. Forest Res. 2016, 31, 148-155. [CrossRef]

41. Erikson, K. A New Species of Trouble: The Human Experience of Modern Disasters; WW Norton \& Company: New York, NY, USA, 1994.

42. Flyvbjerg, B. Making Social Science Matter: Why Social Inquiry Fails and How It Can Succeed Again; Cambridge University Press: Cambridge, UK, 2001.

43. Flyvbjerg, B. Five misunderstandings about case-study research. Qual. Inq. 2006, 12, 219-245. [CrossRef]

44. Mårald, E.; Sandström, C.; Nordin, A. Forest Governance and Management Across Time: Developing a New Forest Social Contract; Routledge: Abingdon, UK, 2017.

45. Beland Lindahl, K.; Sténs, A.; Sandström, C.; Johansson, J.; Lidskog, R.; Ranius, T.; Roberge, J.-M. The Swedish forestry model: More of everything? Forest Policy Econ. 2017, 77, 44-55. [CrossRef]

46. Lidskog, R.; Sundqvist, G.; Kall, A.-S.; Sandin, P.; Larsson, S. Intensive forestry in Sweden: Stakeholders' evaluation of benefits and risk. J. Integr. Environ. Sci. 2013, 10, 145-160. [CrossRef]

47. Lidskog, R.; Löfmarck, E. Managing uncertainty. The forest professionals' claim and epistemic authority in the face of societal and climate change. Risk Manag. 2015, 17, 145-164. [CrossRef]

48. Berglez, P.; Lidskog, R. Foreign, domestic, and cultural factors in climate change reporting. Swedish media coverage of wildfires in three continents. Environ. Commun. 2018. [CrossRef]

49. The County Administrative Board of Västmanland (CAB). Skogsbranden i Västmanland 2014; CAB: Västerås, Sweden, 2014.

50. Swedish Civil Contingencies Agency (MSB). Observatörsrapport. Skogsbranden i Västmanland 2014; MSB: Stockholm, Sweden, 2015.

51. Fire Protection Nerikes. Olycksutredning. Skogsbrand Västmanland; Fire Protection Nerikes: Sala municipality, Sala, Sweden, 2014.

52. Luhmann, N. Risk. A Sociological Theory; Walter de Gruyter: New York, NY, USA, 1993.

53. Swedish Civil Contingencies Agency (MSB). Ansvar, samverkan, handling: Åtgärder för stärkt krisberedskap utifrån erfarenheterna från skogsbranden i Västmanland 2014; MSB: Stockholm, Sweden, 2016.

54. Sjökvist, A.; Strömberg, I. Rapport från Skogsbrandsutredningen; Ministry of Justice: Stockholm, Sweden, 2015.

55. Freudenberg, W.R. Contamination, corrosion and the social order: An overview. Curr. Sociol. 1997, 45, 19-39. [CrossRef]

56. Perrow, C. Normal Accidents: Living with High-risk Technologies. Basic Books: New York, NY, USA, 1984.

57. Doyle, D.P. Window of opportunity. Wilson Q. 1984, 8, 91-101. 